\title{
Struktur Makroalga Pada Ekosistem Lamun Di Kecamatan Tabukan Selatan, Kabupaten Kepulauan Sangihe, Sulawesi Utara \\ (Structure of Macroalgae in Seagrass Ecosystems at South Tabukan District, Sangihe Islands Regency, North Sulawesi)
}

\author{
Irawaty A. Mertosono ${ }^{1)}$, Ratna Siahaan ${ }^{1 *}$ Pience V. Maabuat ${ }^{1)}$ \\ 1) Jurusan Biologi, Fakultas Matematika dan IImu Pengetahuan Alam, \\ Universitas Sam Ratulangi, Manado 95115 \\ *Email korespondensi:ratnasiahaan@unsrat.ac.id
}

Diterima 15 Februari 2019, diterima untuk dipublikasi 28 Februari 2019

\begin{abstract}
Abstrak
Makroalga laut merupakan tumbuhan laut yang tidak memiliki akar, batang, maupun daun sejati. Kegiatan manusia berupa pemanfaatan makroalga, konversi lahan, dan transportasi laut dapat menjadi penyebab penurunan biodiversitas makroalga. Tujuan penelitian ini adalah untuk menganalisis struktur dan distribusi makroalga pada ekosistem lamun di Kecamatan Tabukan Selatan, Kabupaten Kepulauan Sangihe, Sulawesi Utara. Lokasi penelitian di tiga stasiun penelitian yaitu Pantai Karurung - Desa Salurang, Pantai Palareng - Desa Palareng dan Pantai Galoghong - Desa Batuwingkung. Penelitian dilakukan pada NovemberDesember 2018 dengan pengambilan sampel menggunakan metode garis transek (line transect) dengan teknik pencuplikan kuadrat. Makroalga yang ditemukan sebanyak 36 spesies yang terdiri atas 25 spesies Divisi Chlorophyta, sembilan (9) spesies Divisi Rhodophyta dan dua (2) spesies Divisi Phaeophyta. Makroalga Bornetella nitida memiliki Indeks Nilai Penting 39, 24\% mendominasi di lokasi penelitian. Keanekaragaman Shannon-Wiener $\left(H^{\prime}\right)$ spesies makroalga di Stasiun I $\left(H^{\prime}: 3,02\right)$ tergolong tinggi sedangkan pada Stasiun II $\left(H^{\prime}: 2,86\right)$ dan Stasiun III $\left(H^{\prime}: 2,63\right)$ tergolong sedang. Secara keseluruhan, keanekaragaman spesies makroalga di Kecamatan Tabukan Selatang tergolong tinggi $\left(H^{\prime}: 3,00\right)$.

Kata kunci: struktur makroalga, Pantai Karurung, Pantai Palareng, Pantai Galoghong,Tabukan Selatan
\end{abstract}

\begin{abstract}
Marine macroalgae are marine plant-like organisms that has no true roots, stems, or leaves. The human ativities of macroalgae utilization, land conversion, and sea transportation can cause of macroalgae biodiversity decline. The purpose of this study was to analyze the structure and distribution of macroalgae in seagrass ecosystems at South Tabukan District, Sangihe Islands Regency, North Sulawesi. The research locations were at three research stations, i.e. Karurung Beach - Salurang Village, Palareng Beach - Palareng Village and Galoghong Beach - Batuwingkung Village. The study was conducted in NovemberDecember 2018 with line transect method sampling and quadrate sampling technique. Macroalgae were 36 species consists of 25 species of Chlorophyta Division, nine (9) species of Rhodophyta Division and two (2) species of Phaeophyta Division. Macroalga Bornetella nitida had Importance Value Index $39.24 \%$ that dominated research locations. The Shannon-Wiener biodiversity Index $\left(H^{\prime}\right)$ of macroalgae species at Station I ( $H^{\prime}:$ 3.02) was classified as high while Station II ( $H^{\prime}:$ 2.86) and Station III ( $H^{\prime}:$ :2.63) were moderate. Overall, macroalgae species diversity at Tabukan Selatang District was high (H': 3.00).

Keywords: Macroalgae structure, Macroalgae distribution, Karurung Beach, Palareng Beach, Galoghong Beach, South Tabukan
\end{abstract}




\section{PENDAHULUAN}

Makroalga merupakan tumbuhan yang tidak mempunyai akar, batang, maupun daun sejati (Loban dan Harrison 1997; Anggadiredja et al. 2011). Makroalga di Indonesia telah teridentifikasi sebanyak 782 spesies makroalga diantaranya 196 Chlorophyta, 452 Rhodophyta dan 134 Phaeophyta (Anggadiredja et al. 2011). Makroalga ditemukan hidup di perairan yang jernih dan masih terkena sinar matahari hingga ke dasar perairan seperti pada ekosistem lamun. Makroalga dan lamun bersama-sama memiliki berbagai fungsi ekologis penting antara lain sebagai produsen materi organik, sumber makanan langsung bagi konsumen, habitat, tempat reproduksi (nursery), tempat berlindung berbagai jenis organisme lain serta menjaga keseimbangan dan kelestarian keanekaragaman dari biota laut yang ada (Dawes 1998; Riniatsih et al. 2017).

Kepulauan Sangihe merupakan gugusan pulau yang berada dalam wilayah administratif Provinsi Sulawesi Utara yang memiliki potensi sumber daya alam hayati laut yang tinggi. Penelitian ini bertujuan untuk menganalisis struktur makroalga pada ekosistem lamun di Kecamatan Tabukan Selatan, Kabupaten Kepulauan Sangihe. Manfaat penelitian yaitu sebagai data base keanekaragaman makroalga yang penting bagi kesejahteraan manusia.

\section{METODE \\ Waktu dan Tempat Penelitian}

Penelitian dilakukan pada November sampai Desember 2018. Pengambilan sampel dilakukan di zona intertidal pada tiga stasiun yaitu Stasiun I di Pantai Karurung - Desa Salurang, Stasiun II di Pantai Palareng - Desa Palareng, dan Stasiun III di Pantai Galoghong - Desa Batuwingkung, Kecamatan Tabukan Selatan, Kabupaten Kepulauan Sangihe, Sulawesi Utara.
Lokasi penelitian dibagi menjadi 3 stasiun dengan tiga pengulangan. Stasiun I pada titik-titik koordinat 328'04,55"LU dan 125'39'54,46"BT; 0339'05,26"LU dan 12539'56,43"BT; 0339'00,84"LU dan 125'39'54,89"BT; 0339'01,47"'LU dan 12539'57,15"BT.

Stasiun II pada titik-titik koordinat $3^{\circ} 30^{\prime} 39,81^{\prime \prime} \mathrm{LU}$ dan $125^{\circ} 39^{\prime} 15,87^{\prime \prime} B \mathrm{BT}$; $3^{\circ} 30^{\prime} 39,84$ "LU dan $125^{\circ} 39^{\prime} 20.27^{\prime \prime} B T$; $3^{\circ} 30^{\prime} 47,70^{\prime \prime} \mathrm{LU}$ dan $125^{\circ} 39^{\prime} 16,70^{\prime \prime} \mathrm{BT}$; $3^{\circ} 30^{\prime} 47.00^{\prime \prime} \mathrm{LU}$ dan $125^{\circ} 39^{\prime} 22,08^{\prime \prime} B \mathrm{BT}$. Stasiun III di titik-titik koordinat $3^{\circ} 32^{\prime} 06,58^{\prime \prime} \mathrm{LU}$ dan $125^{\circ} 39^{\prime} 34,26$ "BT; 330'07,85'LU dan 125'39'35,07" BT; $3^{\circ} 30^{\prime} 05,74^{\prime \prime}$ LU dan $125^{\circ} 39^{\prime} 35,39^{\prime \prime}$ BT; $3^{\circ} 30^{\prime} 07,32^{\prime \prime}$ LU dan 125³9'36,55" BT (Gambar 1).

Penyiapan spesimen herbarium dan identifikasi dilakukan di lokasi penelitian dan dianalisis kembali di Laboratorium Ekologi, Jurusan Biologi, Fakultas Matematika dan IImu Pengetahuan Alam, Universitas Sam Ratulangi.

\section{Alat dan Bahan}

Alat-alat yang digunakan dalam penelitian ini antara lain: meteran gulung $30 \mathrm{~m}$ dan $100 \mathrm{~m}$, plot $1 \mathrm{~m} \mathrm{x}$ $1 \mathrm{~m}$, refraktometer, $\mathrm{pH}$ meter, kamera, GPS (Global Positioning System), mikroskop stereo, dan alat tulis. Bahan yang digunakan antara lain plastik sampel, dan formalin 3-5 $\%$.

\section{Prosedur Penelitian}

Pengambilan sampel dengan menggunakan metode garis transek (line transect) dengan teknik pencuplikan/sampling kuadrat. Sebanyak tiga garis transek diletakkan di tiap lokasi dengan posisi tegak lurus (vertikal) terhadap garis pantai. Panjang garis transek akan disesuaikan dengan panjang ekosistem lamun. Petak-petak kuadrat berukuran $1 \mathrm{~m} \times 1 \mathrm{~m}$ akan diletakkan di tiap garis transek. Peletakan petakpetak kuadrat pada transek diletakkan secara selang-seling atau sistematis. Jarak antar petak kuadrat berkisar 
antara $15 \mathrm{~m}$ - $50 \mathrm{~m}$ yang juga disesuaikan dengan panjang transek. Banyaknya petak kudrat di transek disesuaikan dengan lebar intertidal. Petak kudarat di transek berjumlah 35 petak. Jarak antar transek berkisar antara $30 \mathrm{~m}-100 \mathrm{~m}$.

Setiap spesies makroalga yang ditemukan ditiap petak kuadrat dihitung jumlahnya. Tiap spesies makroalga diambil dan dimasukkan dalam plastik yang diberi label.
Sampel-sampel tersebut dibersihkan, difoto kemudian diberi larutan formalin 3-5\% untuk diawetkan agar sampel tidak rusak untuk diidentifikasi kembali. Seluruh sampel dibawa ke Laboratorium Ekologi untuk diidentifikasi berdasarkan ciri morfologi dengan acuan antara lain Guiry dan Guiry (2019), Bold dan Wyne (1984), van den Hoek (1995), Trono dan Fortez (1988), dan Prosea (2002).

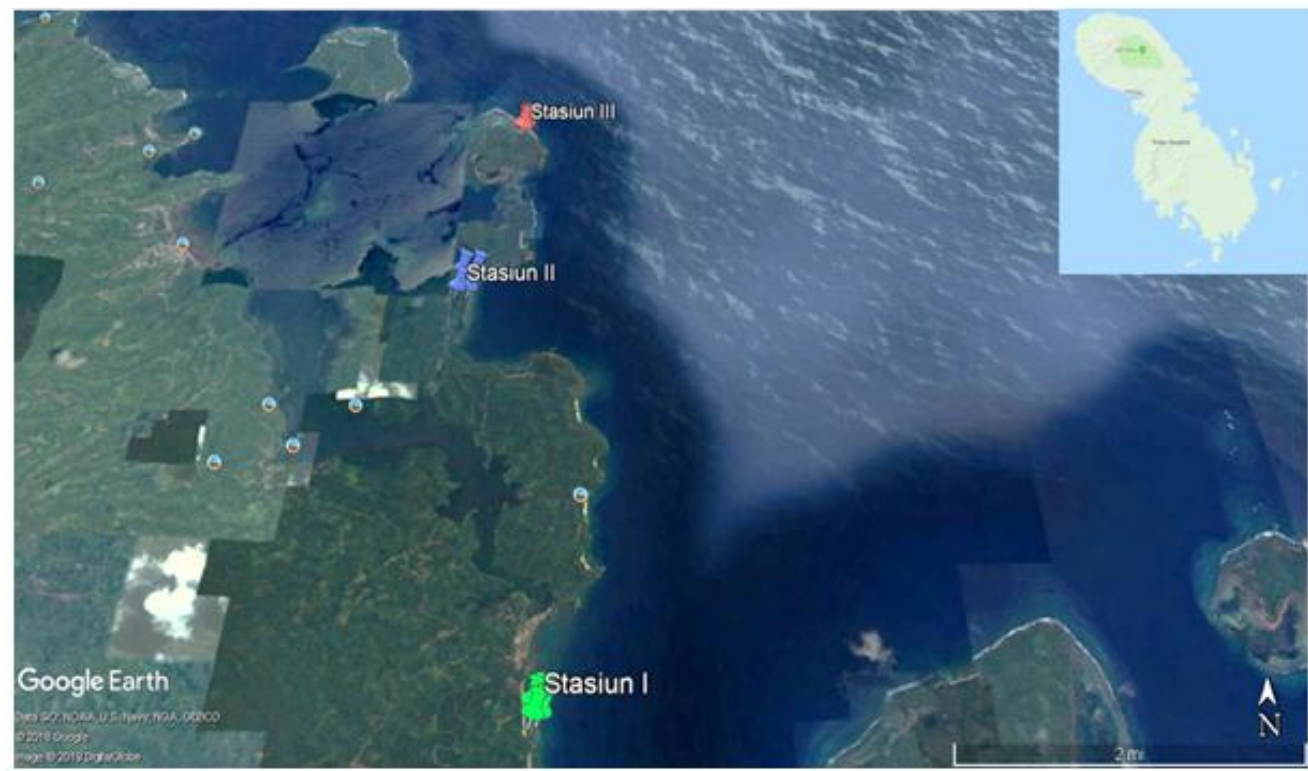

Gambar 1. Peta lokasi penelitian

\section{Analisis Data}

Data dianalisis rumus

dengan Kepadatan menggunakan Relatif, Frekuensi Relatif; Indeks Nilai Penting, dan Indeks Keanekearagaman Shannon-Wiener $\left(\mathrm{H}^{\prime}\right)$.

\section{a. Kepadatan dan Kepadatan Relatif Kepadatan spesies dihitung dengan menggunakan rumus (Stilling, 2012) yaitu:}

$$
\begin{gathered}
\text { Kepadatan spesies }=\mathrm{ni} / \mathrm{A} \\
\operatorname{KR}(\%)=\frac{\mathrm{ni}}{\mathrm{N}} \times 100
\end{gathered}
$$

Dimana:

$\mathrm{ni}=$ Jumlah individu makroalga ke -i dalam transek kuadrat

A = Luas transek kuadrat
$\mathrm{KR}=$ Kepadatan Relatif

$\mathrm{N}=$ Total individu makroalga

b. Frekuensi dan Frekuensi Relatif

Frekuensi kehadiran dan frekuensi relatif dihitung menggunakan rumus (Fachrul, 2007) sebagai berikut:

$$
\mathrm{F}_{\mathrm{i}}=\frac{\mathrm{pi}}{\sum \mathrm{P}} \quad \mathrm{FR}(\%)=\frac{\mathrm{Fi}}{\sum \mathrm{F}} \times 100
$$

Dimana:

$$
\begin{aligned}
\mathrm{pi}= & \text { Banyaknya kuadrat dengan } \\
& \text { spesies ke-i } \\
\mathrm{F}= & \text { Frekuensi } \\
\sum \mathrm{P}= & \text { Jumlah total kuadrat yang diamati } \\
\mathrm{F}_{\mathrm{i}}= & \text { frekuensi kehadiran spesies ke-i } \\
\sum \mathrm{F}= & \text { Jumlah total frekuensi seluruh } \\
& \text { spesies }
\end{aligned}
$$


c. Indeks Nilai Penting (INP)

Indeks Nilai Penting (INP) diperoleh dengan menghitung Kepadatan Relatif dan Frekuensi Relatif (Fachrul 2007).

$$
\mathrm{INP}=\mathrm{KR}+\mathrm{FR}
$$

Dimana:

INP = Indeks Nilai Penting

$\mathrm{KR}=$ Kepadatan Relatif

$\mathrm{FR}=$ Frekuensi Relatif

d. Indeks Keanekaragaman spesies

Keanekaragaman ialah banyaknya spesies makroalga dan penyebaran jumlah individu makroalga dalam tiap spesiesnya. Keanekaragaman spesies makroalga dihitung dengan Indeks Shannon-Wienner (Stilling 2012).

$$
H^{\prime}=-\sum_{n=1}^{s} \text { pi ln pi }
$$

Dimana:

$$
\begin{aligned}
& \mathrm{H}^{\prime}: \text { Indeks Keanekaragaman } \\
& \text { Shannon } \\
& \mathrm{p}_{\mathrm{i}}: \text { : } \text { perbandingan antara jumlah } \\
& \text { individu spesies makroalga } \\
& \text { ke-i (ni ) dengan jumlah total } \\
& \text { individu makroalga (N) } \\
& \mathrm{s} \quad \text { : Jumlah spesies makroalga ke-i }
\end{aligned}
$$

Tingkat keanekaragaman spesies ini diklasifikasikan menjadi tiga (Fachrul, 2007) yaitu:

Jika H' $\leq 1$, keanekaragaman rendah, Jika $\quad 1<\mathrm{H}^{\prime}<3$, keanekaragaman sedang

Jika $\mathrm{H}^{\prime}>3$, keanekaragaman tinggi

\section{HASIL DAN PEMBAHASAN \\ Kekayaan Makroalga}

Kekayaan makroalga yang ditemukan di lokasi penelitian Pantai Karurung, Pantai Palareng, dan Pantai Galoghong terdiri atas tiga divisi, tiga kelas, sembilan ordo, 16 famili, 22 genus dan 36 spesies. Stasiun I memiliki 29 spesies yang termasuk ke dalam tiga divisi yaitu
Chlorophyta (20 spesies), Rhodophyta (tujuh spesies) dan Phaeophyta (dua spesies). Stasiun II memiliki 26 spesies yang tergolong dalam divisi Chlorophyta (delapan spesies), Rhodophyta (enam spesies), dan Phaeophyta (dua spesies). Stasiun III ditemukan 27 spesies makroalga yang terdiri atas Divisi Chlorophyta (delapan spesies), Rhodophyta (tujuh spesies) dan Phaeophyta (dua spesies). Kehadiran makroalga di suatu ekosistem dipengaruhi oleh kemampuan adaptasinya terhadap faktor-faktor lingkungan misalnya cahaya, dan substrat (Luning 1991).

\section{Kepadatan Makroalga}

Secara keseluruhan, sebanyak 10 spesies memiliki kepadatan (ind $/ \mathrm{m}^{2}$ ) rata-rata tertinggi yaitu Amphiroa rigida $(0,84)$, Bornetella nitida $(8,22)$, Bornetella sphaerica $(1,58)$, Caulerpa lentilifera (2,88), Caulerpa taxifolia $(0,73)$, Dictyosphaeria cavernosa $(1,94)$, Gracilaria salicornia $(1,09)$, Halimeda boerneensis (2,42), Mastophora rosea $(0,69)$, dan spesies Padina australis $(0,98)$ pada Perairan Intertidal Tabukan Selatan.

Kepadatan tertinggi pada Stasiun I disumbang oleh Bornetella nitida $(4,50)$ dan terendah oleh Halimeda macroloba $\quad(0,02)$ Makroalga Chlorophyta spesies Halimeda boerneensis merupakan spesies yang memiliki kepadatan tertinggi $(3,50)$ pada Stasiun II. Kepadatan terendah yaitu spesies Halimeda cylindraceae dan Avrainvillea erecta sebesar 0,02. Stasiun III terdapat 27 spesies dimana Bornetella nitida merupakan spesies yang memiliki kepadatan tertinggi 20,76 dan terendah dari Hypnea spinella dan Udotea javensis 0,05.

Ayhuan (2017) menyebutkan bahwa tipe habitat dan dominansi spesies makroalga berpengaruh pada sebaran kepadatan makroalga. Makroalga spesies $B$. nitida memiliki kepadatan yang paling tertinggi di lokasi penelitian disebabkan 
kemapuan adaptasinya yang tinggi. Makroalga ini memiliki holdfast berbentuk seperti akar serabut (Anonim 2016) yang mampu mengkait substrat keras, cangkang biota lain dan patahan karang dengan arus yang deras berombak.

\section{Indeks Nilai Penting}

Indeks Nilai Penting (INP) menunjukkan dominansi suatu spesies makroalga dalam komunitasnya (Rondo, 2011). Spesies yang dominan di Stasiun I, II dan III secara berturut-turut yaitu $B$. nitida $(32,09 \%), H$. boerneensis $(34,50 \%)$, dan $B$. nitida (56,50\%). Makroalga dominan di lokasi penelitian ialah B. nitida dengan INP $39,24 \%$ dan kodominan ialah $H$. boernensis dengan INP 17,78\%.

Dominansi suatu spesies di lingkungan tertentu dipengaruhi oleh berbagai faktor lingkungan. Dominansi makroalga $B$. nitida dan $H$. boerneensis disebabkan oleh faktor-faktor lingkungan seperti substrat, suhu, salinitas, dan $\mathrm{pH}$ yang sesuai terhadap kehadiran dan pertumbuhan makroalga. Kedua spesies tersebut memiliki holdfast yang menyerupai akar serabut yang dapat melekat pada substrat karang mati, batuan ataupun pecahan karang (Anonim 2016; Kadi 1987).

\section{Keanekaragaman Makroalga}

Indeks keanekaragaman makroalga Shannon-wiener $\left(\mathrm{H}^{\prime}\right)$ di lokasi penelitian Stasiun I, II dan III berturut-turut yaitu 3,$02 ; 2,86$ dan 2,63 (Gambar 3). Indeks Keanekaragaman di Stasiun I termasuk tinggi $\left(\mathrm{H}^{\prime}>3\right)$ dan di Stasiun II dan III tergolong sedang $\left(1 \leq \mathrm{H}^{\prime} \leq\right.$ 3). Keanekaragaman makroalga secara keseluruhan di lokasi penelitian termasuk tinggi dengan indeks H' sebesar 3,00 (Gambar 2). Indeks Keanakeragaman tertinggi hingga terendah berturut-turut di Stasiun I, II dan III.

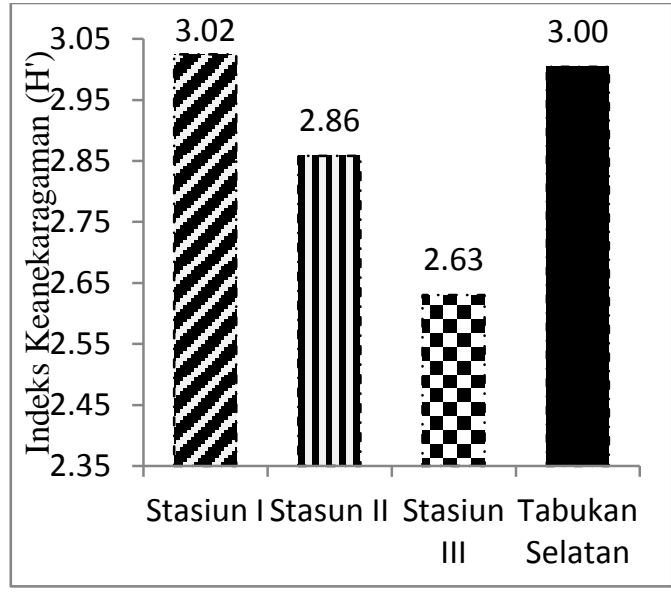

Gambar 2. Nilai H' makroalga

\section{KESIMPULAN}

Makroalga di Kecamatan Tabukan Selatan memiliki jumlah sebanyak 36 spesies yang terdiri atas 25 spesies Divisi Chlorophyta, sembilan spesies Divisi Rhodophyta dan dua spesies Divisi Phaeophyta. Spesies B. nitida (INP 39.24\%) mendominasi pada lokasi penelitian. Indeks Keanekaragaman spesies makroalga di Stasiun I sebesar 3,02 tergolong tinggi sedangkan di Stasiun II sebesar 2,86 dan Stasiun III sebesar 2,63 tergolong sedang. Secara keseluruhan, keanekaragaman spesies makroalga sebesar 3,00 yang tergolong tinggi.

\section{DAFTAR PUSTAKA}

Anggadiredja TJ, Zatnika A, Purwanto H, Istini S (2011) Rumput laut, Penerbit Penebar Swadaya, Jakarta.

Anonim (2016) Detail organisme rumput laut http://coremap.oseanografi.lipi.g o.id/organisme/rumputlaut/6. Diakses pada 30 Januari 2019.

Ayhuan HV (2017) Studi analisis interaksi makroalga dengan parameter lingkungan di Perairan Manokwari Papua Barat, Disertasi. Institut Pertanian Bogor. Bogor.

Bold H, Wyne MJ (1984) Introduction to the algae, Edisi 
ke-2. Prentice Hall, Inc. Englewood Cliff, New Jersey.

Dawes CJ (1998) Marine botany. Edisi ke-2. John Wiley \& Sons, Inc. Tampa, Florida.

Fachrul MF (2007) Metode sampling bioekologi. Bumi Aksara, Jakarta.

Guiry MD, Guiry GM (2019) AlgaeBase. World-wide electronic publication, National University of Ireland, Galway. http://www.algaebase.org;

Diakses pada 2 Januari 2019.

Hoek C. van den, Mann DG, Jahns HM (1995) Algae: an Introduction to Phycology. Cambridge University Press, Cambridge.

Kadi, A. 1987. Cara Mengenal JenisJenis dari Marga Halimeda. Oseana 12(1): $1-12$.

Loban, C.S., P.J. Harrison. 1997. Seaweed Ecology and Physiology. Cambridge University Press, Cambridge.

Luning K (1991) Seaweed: their environment, biogeography, and ecophysiology. John Wiley \& Sons, New York.

Prosea (2002) Plant Resources of South-East Asia 15 (1) Cryptogams: Algae. Prud'homme van Reine, Prosea Fondation, Bogor.

Riniatsih I, Munasik M, Suryono CA, Azizah R, Hartati R, Pribadi R, Subagiyo S (2017) Komposisi makroalga yang berasosiasi di ekosistem padang lamun Pulau Tumpul Lunik, Pulau Rimau Balak dan Pulau Kandang Balak Selatan, Perairan Lampung Selatan. Jurnal Kelautan Tropis 20(2):124-130.

Stilling P (2012) Ecology: global insights and investigations, McGraw-Hill, New York.

Trono GC, Ganzon-Fortes ET (1988) Philippine seaweeds, National Book Store Inc., Manila. 